\title{
Morphometric Analysis of Chin Shape in Inverted Mandible and Mid Symphysis Menti Angle
}

\author{
Sachin Aditya $\mathrm{B}^{1}$ and Yuvaraj Babu K2* \\ ${ }^{1}$ Saveetha Dental college and Hospitals, Saveetha Institute of Medical \\ and Technical Sciences, Saveetha University, Chennai - 600077, India \\ ${ }^{2}$ Assistant professor, Department of Anatomy, Saveetha Dental college and \\ Hospitals, Saveetha Institute of Medical and Technical Sciences, Saveetha University, \\ Chennai - 600077, India
}

\section{ABSTRACT}

In human anatomy, the skull 's facial skeleton, the outer surface of the mandible, is distinguished by a slight ridge in the median line, suggesting the mandibular symphysis or junction line in which the two lateral halves of the mandible usually unite at an early life (1-2 years). This is not a true symphysis, since there is no cartilage between the mandible's two hands. The main aim of the study is to measure the mid symphysis menti angle in the inverted aspect. 30 unsexed dry human skulls were taken from the Department of Anatomy, Saveetha Dental College and Hospital. Protractor was used to measure the mid symphysis menti angle in the inverted aspect of the mandible. The average measurement of mid symphysis menti angle was $76.16^{\circ}$ and the shape of the mental protuberance for most of the samples were oval shaped. Our study has tried to analyse the mid symphysis menti angle and chin shape in the inverted aspect of mandibles, this data may be useful for surgeons in planning their surgery in the mandibular region.

KEY WORDS: MID SYMPHYSIS MENTI ANGLE, MENTAL PROTUBERANCE, MANDIBLE, CHIN SHAPE.

\section{INTRODUCTION}

The human mandible is routinely utilised as a part of the assessment of biological identity in forensic anthropological and odontological practice (Fouhil and El Fouhil, 2012; Rehman, Parveen and Ishaq, 2016). It is morphologically distinct from other primates both in terms of proportions and specific anatomical features(Bennack, 1981). They are also being used since olden time to ascertain the sex of an individual, because

\section{ARTICLE INFORMATION}

${ }^{*}$ Corresponding Author: yuvarajbabu@saveetha.com Received 4th Aug 2020 Accepted after revision 23rd Sep 2020 Print ISSN: 0974-6455 Online ISSN: 2321-4007 CODEN: BBRCBA

Thomson Reuters ISI Web of Science Clarivate Analytics USA and Crossref Indexed Journal

\section{Clarivate
Analytics}

NAAS Journal Score 2020 (4.31) SJIF: 2020 (7.728)

A Society of Science and Nature Publication,

Bhopal India 2020. All rights reserved.

Online Contents Available at: http//www.bbrc.in/

Doi: http://dx.doi.org/10.21786/bbrc/13.8/119 they show sexual dimorphism(G and Vinay, 2013). It is the largest and strongest bone in the face with horizontally curved body that is convexed forwards with two broad rami, which ascend from the posterior end of the body, Therefore it remains the most durable bone of the facial skeleton and retains its shape better than other bones $(\mathrm{G}$ and Vinay, 2013; Batel et al., 2014). The human mandible is also found to resist post mortem damage and forms an important source of information about the sexual dimorphism. It forms the chief articulating segment of the skull(Posso and Donatelli, 2006), Thus it is the platform for dental surgeons to work with.

Different authors have highlighted the utility of odontological strategies in morphological, metric highlights and non-metric qualities in the mandible, including discrete regions, for example, symphyseal morphology and shape, gonial edge, gonial reversal and eversion, ramus flexure, generally shape from circular fourier analysis(7) and separating capacities dependent

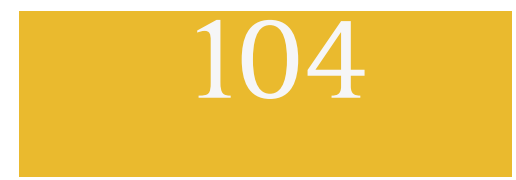


on their measurements among others in the appraisal of biological sex and ancestry $(8,9)$. Most recently, a number of studies used geometric morphometric approaches(Fabre et al., 2014) address issues of biological identity. Previous studies on dried mandibles include study of their angle in mixed population in which the angle varied between 110 degrees to 142 degrees from old to young age people and facial height was also calculated with this bone(Malik et al., 2017).

Although measurements of several thousands of mandibles taken for anthropological purposes have been published, they are actually of little value in some cases. Primarily this can be due to the fact that the technique of measurement has never been standardised and many of the data obtained by those techniques which have been most widely used cannot be compared accurately in cases where direct comparison should be possible. There are only a few publications related to inverted aspect of mandible and midsymphis menti angle, the present study is aimed at morphometrically analysing the chin shape in inverted mandible and mid symphysis menti angle. The need for such type of study is due to increased incidence of accidents where a number of unidentified cases are obtained and these measurements may be useful for their reconstructive procedures.

Our department is passionate about child care, we have published numerous high quality articles in this domain over the past 3 years (Govindaraju, Jeevanandan and Subramanian, 2017a, 2017b; Panchal, Gurunathan and Shanmugaavel, 2017; Ravikumar, Jeevanandan and Subramanian, 2017; Jeevanandan and Govindaraju, 2018; Nair et al., 2018; Ravikumar et al., 2018, 2019; Ravindra et al., 2018, 2019; Subramanyam et al., 2018; Vishnu Prasad et al., 2018; Jeevanandan, Ganesh and Arthilakshmi, 2019; Ramadurai et al., 2019; Ramakrishnan, Dhanalakshmi and Subramanian, 2019; Veerale Panchal, Jeevanandan and Subramanian, 2019; Vignesh et al., 2019; V. Panchal, Jeevanandan and Subramanian, 2019; Samuel, Acharya and Rao, 2020). With this inspiration we planned to pursue research on morphometric analysis of chin shape in inverted mandible and mid symphysis menti angle.

\section{MATERIAL AND METHODS}

For the current study 30 dried unsexed mandibles of the South Indian population were examined from the Department of Anatomy, Saveetha Dental College and Hospital. The shape of mental protuberance and mid symphysis menti-angle was measured using a protractor keeping the mandible in inverted aspect, the measurements were recorded separately for each parameter and the readings were tabulated and statistically analysed.

\section{RESULTS AND DISCUSSION}

In this study out of the 30 samples used, 13 samples had round shaped mental protuberance and the remaining 17 mandibles had oval shaped mental protuberance. The mean value of mid symphysis menti angle is $76.16^{\circ}+$ $2.43^{\circ}$, in which the largest mid symphysis menti angle was $85^{\circ}$ and smallest mid symphysis menti angle was $71^{\circ}$.

Table 1. Minimum, Maximum and average Midsymphysis menti angle in mandible

\begin{tabular}{|l|c|}
\hline & $\begin{array}{c}\text { Mid Symphysis menti } \\
\text { angle in degrees }\end{array}$ \\
\hline Maximum Angle & $85^{\circ}$ \\
\hline Minimum Angle & $71^{\circ}$ \\
\hline $\begin{array}{l}\text { Average value of Mid } \\
\text { symphysis menti angle }\end{array}$ & $76.16^{\circ}+2.43^{\circ}$ \\
\hline
\end{tabular}

Roy in his study of chin shape evaluated the proportion of external chin to identify those with diverse morphology, he used protuberantia mentalis for differentiation but we considered mid symphysis menti angle and mental protuberance, subjects falling between the age group of 18-25 years were selected because most of the mandible growth was completed by that time and SN-MP (facial divergence angle) was the parameter used were mean value for males was $23 \pm 5.9^{\circ}$ and for females it was $24.2 \pm 5^{\circ}$. (Roy et al., 2012).

In a similar study by Maneesha Sharma on morphometric analysis of mandible in Indian population, the author focused on helping in identification of mutilated bodies by determining the sex of the obtained mandible, they also tried to set up some parameters of mandible as indicators of sex in Indian population, for this the length, angle and minimum breadth of mandible were considered and the mean length was $17.22 \mathrm{~cm}$, this study gave $60 \%$ accuracy in sex determination (Sharma et al., 2016). A well established racial difference in the facial mandibular dimension had been found to exist by various researchers in various facial types.

\section{CONCLUSION}

Since most of the research are not being done on mid symphysis menti angle, thus knowing the accurate chin shape and mid symphysis menti angle may prove to be helpful in mandibular surgical procedures for people at a particular area in case of accidents and in case of corrective jaw surgeries performed to enhance appearance.

\section{ACKNOWLEDGEMENTS}

We acknowledge Department of Anatomy for allowing us to use bones from their collection for this study

Conflict of Interest: The author declares that there is no conflict of interest in the present study. 


\section{REFERENCES}

Batel, A. et al. (2014) 'Heterochrony in mandible development of larval shrimp (Decapoda: Caridea)-A comparative morphological SEM study of two carideans', Journal of Morphology, pp. 1258-1272. doi: 10.1002/jmor.20299.

Bennack, D. E. (1981) 'The effects of mandible morphology and photosynthetic pathway on selective herbivory in grasshoppers', Oecologia, pp. 281-283. doi: 10.1007/bf00540615.

Fabre, A.-C. et al. (2014) 'Linear versus geometric morphometric approaches for the analysis of head shape dimorphism in lizards', Journal of morphology, 275(9), pp. 1016-1026.

Fouhil, A. F. E. and El Fouhil, A. F. (2012) 'Development of the Site of Articulation Between the Two Human Hemimandibles (Symphysis Menti)', Embryogenesis. doi: 10.5772/37305.

Govindaraju, L., Jeevanandan, G. and Subramanian, E. M. G. (2017a) 'Comparison of quality of obturation and instrumentation time using hand files and two rotary file systems in primary molars: A single-blinded randomized controlled trial', European journal of dentistry, 11(3), pp. 376-379.

Govindaraju, L., Jeevanandan, G. and Subramanian, E. M. G. (2017b) 'Knowledge and practice of rotary instrumentation in primary teeth among indian dentists: A questionnaire survey', Journal of International Oral Health, 9(2), p. 45.

G, V. and Vinay, G. (2013) 'Sex Determination of Human Mandible Using Metrical Parameters', JOURNAL OF CLINICAL AND DIAGNOSTIC RESEARCH. doi: 10.7860/ jcdr/2013/7621.3728.

Jeevanandan, G., Ganesh, S. and Arthilakshmi (2019) 'Kedo file system for root canal preparation in primary teeth', Indian journal of dental research: official publication of Indian Society for Dental Research, 30(4), pp. 622-624.

Jeevanandan, G. and Govindaraju, L. (2018) 'Clinical comparison of Kedo-S paediatric rotary files vs manual instrumentation for root canal preparation in primary molars: a double blinded randomised clinical trial', European archives of paediatric dentistry: official journal of the European Academy of Paediatric Dentistry, 19(4), pp. 273-278.

Malik, S. et al. (2017) 'The Study on the Prevalance of Retromolar Foramen of Adult Dried Mandibles in Uttarakhand Northern Region of India and Its Clinical Significance', Journal of Medical Science And Clinical Research. doi: 10.18535/jmscr/v5i10.105.

Nair, M. et al. (2018) 'Comparative evaluation of postoperative pain after pulpectomy with k-files, kedo-s files and mtwo files in deciduous molars -a randomized clinical trial', Brazilian Dental Science, 21(4), p. 411. Panchal, V., Gurunathan, D. and Shanmugaavel, A. K. (2017) 'Smartphone application as an aid in determination of caries risk and prevention: A pilot study', European journal of dentistry, 11(4), pp. 469474.

Panchal, V., Jeevanandan, G. and Subramanian, E. (2019) 'Comparison of instrumentation time and obturation quality between hand K-file, H-files, and rotary Kedo-S in root canal treatment of primary teeth: A randomized controlled trial', Journal of the Indian Society of Pedodontics and Preventive Dentistry, 37(1), pp. 75-79.

Panchal, V., Jeevanandan, G. and Subramanian, E. M. G. (2019) 'Comparison of post-operative pain after root canal instrumentation with hand K-files, H-files and rotary Kedo-S files in primary teeth: a randomised clinical trial', European archives of paediatric dentistry: official journal of the European Academy of Paediatric Dentistry, 20(5), pp. 467-472.

Posso, S. and Donatelli, R. (2006) 'Skull and Mandible Formation in the Cuckoo (Aves, Cuculidae): Contributions to the nomenclature in avian osteology and systematics', European Journal of Morphology, pp. 163-172. doi: 10.1080/09243860500315507.

Ramadurai, N. et al. (2019) 'Effectiveness of 2\% Articaine as an anesthetic agent in children: randomized controlled trial', Clinical oral investigations, 23(9), pp. 3543-3550.

Ramakrishnan, M., Dhanalakshmi, R. and Subramanian, E. M. G. (2019) 'Survival rate of different fixed posterior space maintainers used in Paediatric Dentistry - A systematic review', The Saudi dental journal, 31(2), pp. 165-172.

Ravikumar, D. et al. (2018) 'DNA profiling of Streptococcus mutans in children with and without black tooth stains: A polymerase chain reaction analysis', Dental research journal, 15(5), p. 334.

Ravikumar, D. et al. (2019) 'Evaluation of McNamara's analysis in South Indian (Tamil Nadu) children between 8-12 years of age using lateral cephalograms', Journal of oral biology and craniofacial research, 9(2), pp. 193-197.

Ravikumar, D., Jeevanandan, G. and Subramanian, E. M. G. (2017) 'Evaluation of knowledge among general dentists in treatment of traumatic injuries in primary teeth: A cross-sectional questionnaire study', European journal of dentistry, 11(2), pp. 232-237.

Ravindra, V. et al. (2018) 'A comparative evaluation between dermatoglyphic patterns and different terminal planes in primary dentition', Journal of clinical and experimental dentistry, 10(12), pp. e1149-e1154. 
Ravindra, V. et al. (2019) 'A comparative evaluation between cheiloscopic patterns and the permanent molar relationships to predict the future malocclusions', Journal of clinical and experimental dentistry, 11(6), pp. e553-e557.

Rehman, D.-E.-S., Parveen, N. and Ishaq, I. (2016) 'Symphysis menti: A strong indicator of osteoporosis', Journal of Oral and Maxillofacial Radiology, p. 62. doi: 10.4103/2321-3841.196349.

Roy, A. S. et al. (2012) 'Jaw Morphology and Vertical Facial Types: A Cephalometric Appraisal', Journal of Orofacial Research, pp. 131-138. doi: 10.5005/jpjournals-10026-1029.

Samuel, S. R., Acharya, S. and Rao, J. C. (2020) ‘School Interventions-based Prevention of Early-Childhood Caries among 3-5-year-old children from very low socioeconomic status: Two-year randomized trial', Journal of public health dentistry, 80(1), pp. 51-60.

Sharma, M. et al. (2016) 'A morphometric study of the human mandible in the Indian population for sex determination', Egyptian Journal of Forensic Sciences, pp. 165-169. doi: 10.1016/j.ejfs.2015.01.002.

Subramanyam, D. et al. (2018) 'Comparative evaluation of salivary malondialdehyde levels as a marker of lipid peroxidation in early childhood caries', European journal of dentistry, 12(1), pp. 67-70.

Vignesh, R. et al. (2019) 'Management of Complicated Crown-Root Fracture by Extra-Oral Fragment Reattachment and Intentional Reimplantation with 2 Years Review', Contemporary clinical dentistry, 10(2), pp. 397-401.

Vishnu Prasad, S. et al. (2018) 'Report on oral health status and treatment needs of 5-15 years old children with sensory deficits in Chennai, India', Special care in dentistry: official publication of the American Association of Hospital Dentists, the Academy of Dentistry for the Handicapped, and the American Society for Geriatric Dentistry, 38(1), pp. 58-59. 